\title{
Levels of Metals in Hair in Childhood: Preliminary Associations with Neuropsychological Behaviors
}

\author{
Margarita Torrente ${ }^{1,2, *}$, Mireia Gascon ${ }^{3,4,5}$, Martine Vrijheid ${ }^{3,4,5}$, Jordi Sunyer ${ }^{3,4,5,6}$, \\ Joan Forns ${ }^{3,4,5}$, José L. Domingo ${ }^{1}$ and Martí Nadal ${ }^{1}$
}

1 Laboratory of Toxicology and Environmental Health, School of Medicine, Institut d'Investigació Sanitària Pere Virgili (IISPV), "Rovira i Virgili” University, Reus, Catalonia 43201, Spain; E-Mails: joseluis.domingo@urv.cat (J.L.D.); marti.nadal@urv.cat (M.N.)

2 Research Center for Behavior Assessment (CRAMC), Department of Psychology, "Rovira i Virgili" University, Tarragona, Catalonia 43007, Spain

3 Centre for Research in Environmental Epidemiology (CREAL), Barcelona, Catalonia 08003, Spain; E-Mails: mgascon@creal.cat (M.G.); mvrijheid@creal.cat (M.V.); jsunyer@creal.cat (J.S.); jforns@creal.cat (J.F.)

4 Hospital del Mar Research Institute (IMIM), Barcelona, Catalonia 08003, Spain

5 Spanish Consortium for Research on Epidemiology and Public Health (CIBERESP), Barcelona, Catalonia 08036, Spain

6 "Pompeu Fabra" University (UPF), Barcelona, Catalonia 08002, Spain

* Author to whom correspondence should be addressed; E-Mail: margarita.torrente@urv.cat; Tel.: +34-977-758-933; Fax: +34-977-759-322.

Received: 8 October 2013; in revised form: 20 December 2013 / Accepted: 20 December 2013 / Published: 30 December 2013

\begin{abstract}
For more than 100 years, an electrochemical plant has been operating in Flix (Catalonia, Spain) by the Ebro River. Its activities have originated a severe accumulation of environmental contaminants (metals, organochlorinated pesticides and radionuclides) in sediments of the Flix reservoir, while mercury $(\mathrm{Hg})$ has been also frequently released to the air. Environmental exposure to industrial pollutants has been associated with decreased intelligence and behavioral problems. In the present study, we assessed, in 53 children living in the village of Flix and the surroundings, the relationships between the concentrations of a number of trace elements (As, Be, Cd, Cs, Hg, Mn, Ni, Pb, Sn, Tl, U and $\mathrm{V}$ ) in hair and the levels of testosterone in blood, with respect to potential neuropsychological alterations. Lead $(\mathrm{Pb})$ and $\mathrm{Hg}$ showed the highest mean concentrations in hair samples. However, the current $\mathrm{Hg}$ levels were lower than those previously found in
\end{abstract}


children living in the same zone, while the concentration of the remaining elements was similar to those reported in the scientific literature. The outcomes of certain neuropsychological indicators showed a significant correlation with metals, such as $\mathrm{Pb}$ and uranium (U). More specifically, these elements were negatively correlated with working memory and hit reaction time, suggesting impulsivity. In summary, although $\mathrm{Pb}$ and $\mathrm{U}$ concentrations in hair were within standard levels, both metals could be correlated with certain, but minor, neuropsychological alterations in the childhood population of Flix. These findings should be confirmed by future birth cohort studies, with bigger study populations and using more complex statistical analyses, focused on human exposure to these specific elements.

Keywords: heavy metals; environmental exposure; human hair; testosterone; n-back; working memory; impulsivity; finger-tapping

\section{Introduction}

For more than 100 years, a chlor-alkali plant has been operating in the village of Flix (Catalonia, Spain) by the Ebro River. During the past few decades, this facility has been dumping industrial wastes into a reservoir located adjacently, resulting in the accumulation of sediments with very high concentrations of metals, organic compounds and radionuclides [1]. In addition, high atmospheric levels of hexachlorobenzene (HCB) have been detected in Flix. Serum concentrations of HCB were found to be the highest ever reported in human general populations [2]. Environmental contaminants may be incorporated into the human body through direct pathways, such as soil ingestion, dermal absorption and air inhalation. In addition, human intake of drinking water and foodstuffs (including vegetables and cattle from the surroundings) is also one of the most important routes of exposure [1]. In recent years, some attention has been paid to the levels of environmental pollutants in the surroundings of Flix $[3,4]$. A number of studies on human health risk assessment have been conducted, prior to the extraction of the contaminated sludge [1,5].

Human biomonitoring is defined as the direct measurement of people's exposure to environmental contaminants by measuring chemical substances or their metabolites in biological tissues, such as blood, urine or other specimens [6]. The development of new methodologies and modern analytical techniques has allowed for the use of other matrices, which are less or non-invasive. Among these, human hair is a suitable monitor for the detection of medical drugs and drugs of abuse and the assessment of trace element deficiency [7,8]. Furthermore, human hair has been especially selected for its suitability to assess human exposure to metals in general and mercury, in particular. Biomonitoring studies have been previously conducted in Flix in order to measure the levels of mercury (Hg) in children's hair $[9,10]$. However, no information regarding the current exposure to $\mathrm{Hg}$ or other elements is currently available.

Environmental exposure to industrial pollutants has been associated with lowered intelligence and behavioral problems [11]. Among other environmental toxic agents, metals have received much attention, as they have been related to neurotoxic effects in animals and humans [12]. In particular, 
children and aged people are especially vulnerable populations, even at moderate levels of exposure. However, the real mechanisms of metal neurotoxicity are poorly understood. Furthermore, the presence of excessive levels of toxic and essential elements in the human body has been associated not only with potential cognitive alterations, but also with psychiatric disorders in children [13]. Indeed, some authors have suggested the need to determine the body burdens of environmental toxicants, as well as their dietary intake, to partially explain psychiatric disturbances [13].

The relationship between brain and the endocrine system is currently more widely understood. Brain contains receptors for androgens and estrogens, being capable of synthesizing and metabolizing these steroids, while hormones impact on neurotrophic factors and effect cognitive behavior [14]. Gonadal steroid hormones become elevated during puberty, sculpting the adolescent brain in both females and males. Furthermore, it has been recognized that the actions of pubertal hormones during adolescence may have long-lasting consequences [15], while there is also evidence of a role of testosterone on cognition [14].

Based on the above, the present study was aimed at analyzing the concentrations of a number of trace elements in hair samples and the levels of testosterone in blood samples from children (aged 12-13) living in Flix and surrounding villages. The relationship between those parameters and different neuropsychological alterations, as well as cognitive and psychiatric variables was also investigated.

\section{Experimental Section}

\subsection{Subjects}

In 1997, a birth cohort was initiated in Flix (Catalonia, Spain) and surrounding villages, with the aim of assessing the potential adverse health effects of exposure to environmental pollutants, particularly persistent organic pollutants, such as $\mathrm{HCB}$, and $\mathrm{Hg}$. All pregnant women delivering at the main hospital of the evaluated area between 1997 and 1999 were invited to participate in the study, of which 102 were finally recruited. Their children were followed-up upon at the age of 1 and 4 years (17.6\% of lost to follow-up). At 12-13 years old, all children from the cohort were invited to participate in a subsequent follow-up campaign. Forty-one of them $(40.2 \%)$ accepted the invitation, joining the study. In the area under evaluation, there is only one high-school where all these children attend. In order to increase the statistical power, classmates of these children were also invited to participate in the study, and 19 of them were added. All parents were informed of the study and signed the consent form.

\subsection{Data Collection}

Children and their parents completed a general questionnaire prepared to obtain information on SES (socioeconomic status) according to parents' workplace, house conditions, the lifestyle of the parents (cigarette and alcohol consumption) and that of the child (physical activity, diet and cigarette and alcohol consumption) and the respiratory health and sexual development of the child (Tanner scale) [16,17]. The United Kingdom Registrar General's 1990 classification was used to group subjects by social class according to maternal and paternal occupation coded using the International Standard Classification of Occupations (ISCO-88) [18] Social class was grouped into six categories. 
Four were created according to maternal occupation (professional, skilled, non-skilled and unemployed), and unemployed women were categorized into three groups according to their husband's occupation [3]. Hair samples from 53 children were collected for the determination of the metal content, while 44 of those also donated blood for testosterone analysis. Finally, the neuropsychological development of the children was evaluated with different tests, as described below.

\subsection{Hair Analysis}

Hair samples were cut from an area close to the occipital region of the scalp. Samples were washed and digested following a previously reported methodological procedure [19]. Briefly, approximately $150 \mathrm{mg}$ of each sample were treated with $2 \mathrm{~mL}$ of nitric acid $65 \%$ (Suprapur, Merck, Darmstadt, Germany) for $8 \mathrm{~h}$ at room temperature and 8 additional hours at $80{ }^{\circ} \mathrm{C}$. Subsequently, the extracts were diluted to $10 \mathrm{~mL}$ and frozen in glass tubes until analysis [20]. The concentration of arsenic (As), beryllium $(\mathrm{Be})$, cadmium $(\mathrm{Cd})$, cesium $(\mathrm{Cs})$, mercury $(\mathrm{Hg})$, manganese $(\mathrm{Mn})$, nickel $(\mathrm{Ni})$, lead $(\mathrm{Pb})$, tin $(\mathrm{Sn})$, thallium $(\mathrm{Tl})$, uranium $(\mathrm{U})$ and vanadium $(\mathrm{V})$ were determined by inductively coupled plasma-mass spectrometry (ICP-MS, Perkin Elmer Elan 6000, Waltham, MA, USA). Quality control/quality assurance (QA/QC) was conducted by analyzing standards (Lobster hepatopancreas, NRC Canada, TORT-2) and blanks every 10 samples. The limits of detection were: $0.003 \mu \mathrm{g} / \mathrm{g}$ for Be and $\mathrm{Cs} ; 0.007 \mu \mathrm{g} / \mathrm{g}$ for $\mathrm{U} ; 0.03 \mu \mathrm{g} / \mathrm{g}$ for $\mathrm{Cd}, \mathrm{Mn}, \mathrm{Pb}$ and Tl; $0.06 \mu \mathrm{g} / \mathrm{g}$ for $\mathrm{Sn} ; 0.13 \mu \mathrm{g} / \mathrm{g}$ for As, $\mathrm{Hg}$ and $\mathrm{Ni}$; and $0.33 \mu \mathrm{g} / \mathrm{g}$ for $\mathrm{V}$. Recovery percentages varied between $70 \%$ and $120 \%$ (Ni and $\mathrm{Hg}$, respectively).

\subsection{Testosterone Analysis}

Fasting morning blood samples were collected early in the morning (8:00-10:00 AM) at ABS-Flix, the primary healthcare center of Flix. Serum of each participant was aliquoted to $0.5 \mathrm{~mL}$. Samples were analyzed within the extraction day. Total testosterone measurement was performed using an Access (Beckman Coulter, Fullerton, CA, USA) automated multianalyte analyzer (LXi-725 integrated), using the instructions of the deliverer. The limit of detection ranged from $0.35-55.5 \mathrm{nmol} / \mathrm{L}$.

\subsection{Neuropsychological Evaluation}

In the present study, we assessed several aspects of neuropsychological development. These included various cognitive domains related to prefrontal cortex function and motor function (working memory, flexibility, verbal fluency and motor functioning) and behavioral outcomes linked to disruptive behaviors in children. The cognitive evaluation consisted of 5 different neuropsychological tests (n-back, Trail Making Test-B (TMT-B), semantic and phonetic fluency and finger-tapping test (FTT)).

The n-back test is a continuous performance task used to measure a part of working memory and control attention [21]. The visual n-back task consisted of a series of 4 different stimuli (numbers and words) presented in the center of the screen. All participants were required to press the "target" button when the target was shown on the screen. In the 1-back condition, the target was any stimulus identical to the stimulus immediately preceding it. In the 2-back condition, the target was any stimulus identical 
to the one presented two trials back. In the 3-back condition, the target was any stimulus identical to the one presented three trials back. Six different hit reaction times (HRTs) were computed; one for each condition (1-, 2- and 3-back) and stimulus (numbers and words). In addition, we also calculated the sensitivity index detectability (d') for each block separately. This index derives from signal detection theory and allows for the distinction of signal and noise, where a higher $d$ ' indicates more accurate performance [22]. We computed a d' score for each of the 6 blocks separately. We also used the TMT-B test to assess cognitive flexibility and executive function [23]. This test requires drawing lines sequentially, connecting numbers and letters, which are encircled and distributed on a paper sheet. The score represents the amount of time required to complete the task.

Semantic and phonetic fluency tests consisted of asking children to say words beginning with a specific letter or words within a specific semantic category (each one within one minute). These tests reflect frontal and frontotemporal areas of activation, respectively [24]. The FTT is a neuropsychological test that examines motor functioning (specifically), motor speed and lateralized coordination [25,26].

Moreover, we evaluated several aspects of children's behavior. On the one hand, children completed the Strengths and Difficulties Questionnaire (SDQ) [27]. This is a brief behavioral screening questionnaire for children aged between 3 and 16 years. The 25 items are divided into 5 subscales: emotional symptoms ( 5 items), added together to generate a total difficulties score (based on 20 items), conduct problems (5 items), hyperactivity/inattention (5 items), peer relationship problems (5 items) and prosocial behavior (5 items). On the other hand, we assessed attention deficit hyperactivity disorder (ADHD) symptomatology using the ADHD Criteria of Diagnostic and Statistical Manual of Mental Disorders, Fourth Edition (ADHD-DSM-IV) form [28]. The questionnaire was filled-out by the teachers. ADHD-DSM-IV consists of a list of 18 symptoms categorized under two separate symptom groups: inattention (9 symptoms) and hyperactivity/impulsivity (9 symptoms). Each ADHD-DSM-IV item is rated on a 4-point scale $(0=$ never or rarely; $1=$ sometimes; $2=$ often, and $3=$ very often $)$. We analyzed the inattention scale (IA) and the hyperactivity/impulsivity scale (HI) as continuous variables, where higher scores indicate higher symptomatology (worse score).

\subsection{Statistical Analysis}

Potential correlations between metal levels in children's hair, testosterone concentrations in blood and the results of neuropsychological indicators were assessed by Spearman correlations. We also tested the correlation of SES (according to the parents' workplace), cigarette consumption by the child and his/her family and the Tanner scale about physical development in children with exposure (metals) with outcomes (testosterone levels and neuropsychobiological indicators). Since no statistically significant correlations between SES and cigarette consumption were found with any other variable, both parameters were not included as co-variables. Significance was set at $p<0.05$. The statistical software, $\operatorname{SPSS}^{\odot}$ v15.0, was used for data treatment. For those elements with metal levels under the limit of detection (LOD), we assumed concentrations equal to one-half of the respective LOD (ND = 1/2LOD; ND, not detected). 


\section{Results and Discussion}

\subsection{Concentrations of Metals in Hair and Levels of Testosterone in Blood}

Metal concentrations in hair samples of 53 children living in Flix and the surroundings villages are depicted in Figure 1. Lead and $\mathrm{Hg}$ showed the highest levels (mean values: 0.66 and $0.47 \mu \mathrm{g} / \mathrm{g}$, respectively; median values: 0.40 and $0.36 \mu \mathrm{g} / \mathrm{g}$, respectively). Thallium was not detected in any sample, while Cs was detected only in one sample. In turn, $\mathrm{Cd}$ and $\mathrm{V}$ showed detectable concentrations in two of the 53 samples.

Figure 1. Metal concentrations (mean values in $\mu \mathrm{g} / \mathrm{g}$ ) in hair samples of children living in the Flix area (Catalonia, Spain) $(n=53)$. Outliers $(>1.5$-box length below the 25 th percentile or above the 75th percentile) are shown as circles, while extreme cases ( $>3$-box length below the 25 th percentile or above the 75 th percentile) are identified as asterisks.
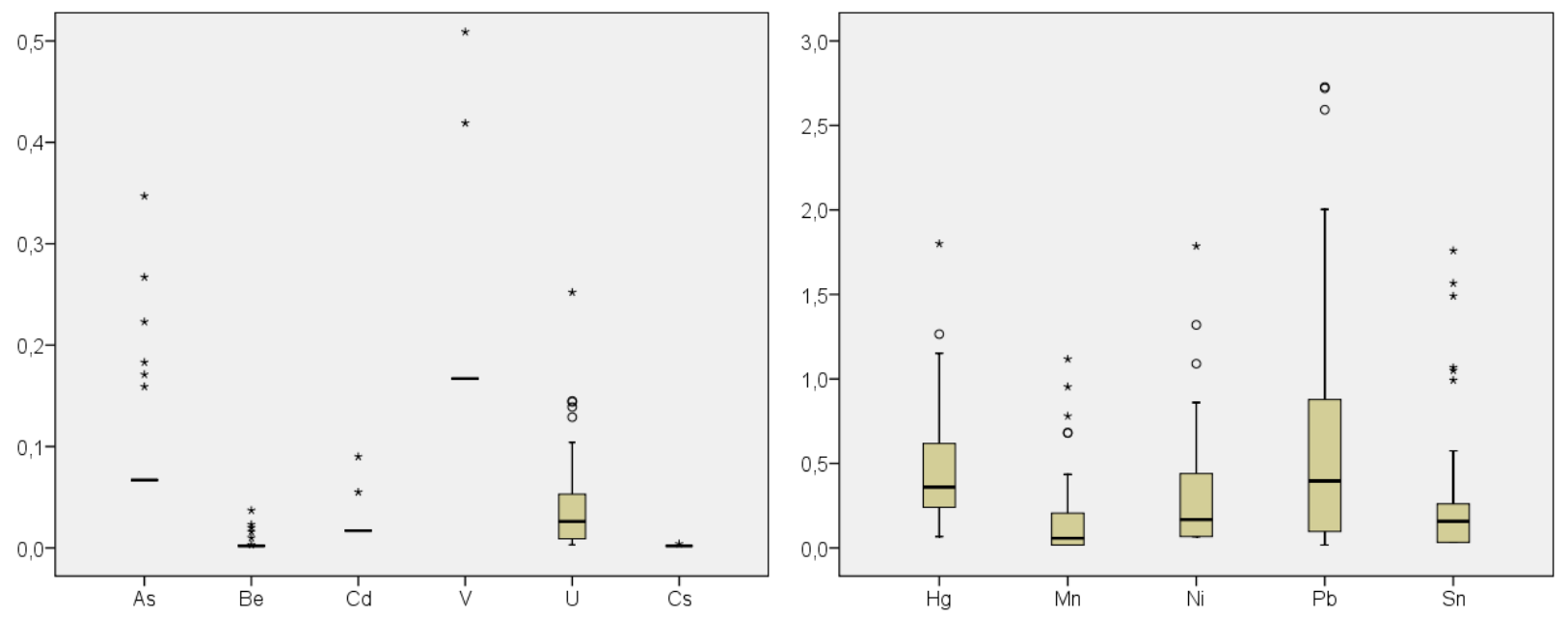

In the current study, $\mathrm{Hg}$ levels (between ND to $1.8 \mu \mathrm{g} / \mathrm{g}$ ) were slightly lower than those previously reported for children living in Flix and surrounding villages. Montuori, et al. [9] reported a total $\mathrm{Hg}$ mean concentration of $1.09 \mu \mathrm{g} / \mathrm{g}$ (median: $0.72 \mu \mathrm{g} / \mathrm{g}$ ) in the same birth cohort, when they were four years old. Mercury levels were significantly higher than those observed in a reference population (Menorca, Spain) (mean: $0.72 \mu \mathrm{g} / \mathrm{g}$; median: $0.48 \mu \mathrm{g} / \mathrm{g}$ ). In 1996, Batista et al. [10] reported a geometric mean concentration of $0.77 \mu \mathrm{g} / \mathrm{g}$ in hair of children aged 6-16 living in Tarragona County, $80 \mathrm{~km}$ from Flix. Similar hair levels of $\mathrm{Hg}$ have been reported in children living in a zone, Tarragona County, under the potential impact of a hazardous waste incinerator, where mean values of $0.73,0.70$ and $0.56 \mu \mathrm{g} / \mathrm{g}$ were found in 1998, 2002 and 2007, respectively [19,20,29]. In Italy, Deroma et al. [30] reported significantly higher levels of total mercury in hair from 77 children living near the Marano-Grado Lagoon with respect to the concentrations found in 72 children living inland (0.88 vs. $0.57 \mu \mathrm{g} / \mathrm{g}$ ). Similarly to Flix, a chlor-alkali plant is located in the lagoon area, where high $\mathrm{Hg}$ levels have been observed in sediments (up to $11-14 \mu \mathrm{g} / \mathrm{g}$ ). In the Russian Republic of Tatarstan, Sitdikov et al. [31] analyzed the levels of some toxic and essential elements in hair of girls (aged 7-9 years) living in rural areas. The mean $\mathrm{Hg}$ concentration was $0.41 \mu \mathrm{g} / \mathrm{g}$ (range: $0.14-0.89 \mu \mathrm{g} / \mathrm{g}$ ), while the levels of other metals were very similar to those found in the current study. In Brazil, 
the mean concentration of $\mathrm{Hg}$ in hair samples from 167 healthy students, aged 12-18 years, was found to be $0.14 \mu \mathrm{g} / \mathrm{g}$, ranging from 0.004 to $0.87 \mu \mathrm{g} / \mathrm{g}$ [32]. Lakshmi Priya and Geetha [33] reported a mean $\mathrm{Hg}$ concentration of $0.37 \mu \mathrm{g} / \mathrm{g}$ in 50 control children (age: 4-12 years), when studying the metal body burdens in children with autism. In turn, total mercury levels in Czech children were observed to be relatively low, with median values ranging $0.13-0.26 \mu \mathrm{g} / \mathrm{g}$ in the period 1996-2008 [34]. In contrast, mean Hg levels in hair of Spanish preschool children have been reported to be among the highest values in non-exposed populations. In Menorca and Ribera d'Ebre (Catalonia), $\mathrm{Hg}$ mean levels in hair were found to be 0.71 and $1.09 \mu \mathrm{g} / \mathrm{g}$, respectively [35], while that in Granada population was $0.96 \mu \mathrm{g} / \mathrm{g}$ [36]. These concentrations have been associated with the consumption of relatively higher amounts of fish by the Spanish general population [20,35].

Regarding the remaining analyzed elements, the current concentrations in hair samples from Flix children were of the same order of magnitude as those reported in the scientific literature in non-exposed children $[31,37,38]$. When analyzing the metal concentrations in hair according to the gender, no significant differences were noted between boys and girls (Table 1). This is in agreement with the findings of Dongarra et al. [37], who reported non-significant differences for the same elements in the hair of 137 children, aged 11-13 years, living in Palermo (Sicily, Italy). The only exception was $U$, which presented significantly higher levels in boys than in girls.

Table 1. Metal concentrations (in $\mu \mathrm{g} / \mathrm{g}$ ) in human hair of 53 children of Flix, according to gender.

\begin{tabular}{|c|c|c|c|c|c|c|}
\hline Gender & Metal & Mean & SD & Median & Minimum & Maximum \\
\hline \multirow{12}{*}{$\begin{array}{c}\text { BOYS } \\
(n=18)\end{array}$} & As & 0.078 & 0.047 & 0.067 & ND & 0.267 \\
\hline & $\mathrm{Be}$ & 0.004 & 0.006 & 0.0020 & ND & 0.023 \\
\hline & $\mathrm{Cd}$ & ND & ND & ND & ND & ND \\
\hline & $\mathrm{Hg}$ & 0.474 & 0.310 & 0.407 & ND & 1.152 \\
\hline & $\mathrm{Mn}$ & 0.132 & 0.218 & 0.017 & ND & 0.682 \\
\hline & $\mathrm{Ni}$ & 0.260 & 0.285 & 0.117 & ND & 1.090 \\
\hline & $\mathrm{Pb}$ & 0.796 & 0.873 & 0.403 & 0.037 & 2.728 \\
\hline & $\mathrm{Sn}$ & 0.230 & 0.411 & 0.055 & ND & 1.566 \\
\hline & $\mathrm{Tl}$ & ND & ND & ND & ND & ND \\
\hline & V & 0.186 & 0.081 & 0.167 & ND & 0.509 \\
\hline & $\mathrm{U}$ & 0.053 & 0.040 & 0.048 & ND & 0.139 \\
\hline & $\mathrm{Cs}$ & 0.002 & 0.0005 & 0.002 & ND & 0.004 \\
\hline \multirow{12}{*}{$\begin{array}{l}\text { GIRLS } \\
(n=35)\end{array}$} & As & 0.088 & 0.059 & 0.067 & ND & 0.347 \\
\hline & $\mathrm{Be}$ & 0.004 & 0.006 & 0.002 & ND & 0.037 \\
\hline & $\mathrm{Cd}$ & 0.020 & 0.014 & 0.017 & ND & 0.090 \\
\hline & $\mathrm{Hg}$ & 0.474 & 0.382 & 0.356 & ND & 1.800 \\
\hline & $\mathrm{Mn}$ & 0.194 & 0.269 & 0.103 & ND & 1.117 \\
\hline & $\mathrm{Ni}$ & 0.531 & 1.234 & 0.171 & ND & 7.267 \\
\hline & $\mathrm{Pb}$ & 0.592 & 0.797 & 0.304 & ND & 3.747 \\
\hline & $\mathrm{Sn}$ & 0.325 & 0.407 & 0.205 & ND & 1.759 \\
\hline & $\mathrm{Tl}$ & ND & ND & ND & ND & ND \\
\hline & V & 0.174 & 0.042 & 0.167 & ND & 0.419 \\
\hline & $\mathrm{U}$ & 0.037 & 0.052 & 0.019 & ND & 0.252 \\
\hline & $\mathrm{Cs}$ & ND & ND & ND & ND & ND \\
\hline
\end{tabular}

SD: standard deviation; ND: not detected. 
A specific analysis of testosterone according to gender was also conducted. The mean level in boys was in the prepubescent-adult range, while that in girls was within the typical range for adults. As expected, boys presented significantly higher levels of testosterone than girls (Table 2). Puberty begins through a sequencing of maturational changes that are being regulated by neuroendocrine and hormonal factors that, in turn, act under genetic and environmental influences [39,40].

Table 2. Testosterone levels (in nmol/L) in blood of children living in the area of Flix.

\begin{tabular}{cccccc}
\hline Group & Mean & SD & Median & Minimum & Maximum \\
\hline ALL $(n=44)$ & 5.57 & 6.61 & 1.49 & 0.49 & 23.49 \\
BOYS $(n=16)$ & $13.23 *$ & 5.19 & 13.00 & 2.03 & 23.49 \\
GIRLS $(n=28)$ & 1.20 & 0.36 & 1.14 & 0.49 & 2.16 \\
\hline
\end{tabular}

SD: standard deviation. * Significant differences between boys and girls at $p<0.001$.

\subsection{Relationship between Metals in Hair and Sexual Development}

Mercury levels in hair were positively correlated with sexual maturation in boys, more specifically with the hairiness in armpits $(r=0.658, p=0.006)$. Lead levels had a positive correlation with the girls' sexual maturation ( $r=0.463, p=0.009$ ), evidencing that girls who had already started menstruation showed higher $\mathrm{Pb}$ levels. It should be noted that the association between $\mathrm{Pb}$ and iron $(\mathrm{Fe})$ has been largely described [41-43]. These two metals share a common intestinal transporter that is upregulated during iron deficiency [42]. Levels of $\mathrm{Pb}$ and $\mathrm{Fe}$ in blood are closely related, especially in children with no evidence of Fe-deficient anemia [43]. Therefore, a minimal change in serum Fe levels may derive changes in blood $\mathrm{Pb}$ concentrations [43]. Since a clear decrease in blood lead concentration has been found with iron repletion [42], Fe fortification has been even proposed to treat lead overexposure. Taking all the above into account, we here suggest that, after menstruation, girls present a certain decrease in their Fe levels, which would turn into an increase in $\mathrm{Pb}$ absorption.

\subsection{Relationship between Metals in Hair and Neuropsychological Tests}

Table 3 summarizes the correlation between the outcomes of the neuropsychological indicators and hair concentrations of $\mathrm{Hg}, \mathrm{Mn}, \mathrm{Pb}$ and $\mathrm{U}$, the only metals with significant correlations between both parameters. Mercury was negatively correlated with peer relationship problems, measured by the SDQ questionnaire $(r=-0.373, p=0.008)$, reflecting lower relationship problems in children with higher Hg levels. No other correlations were found in relation to $\mathrm{Hg}$ levels in the present population. Myers et al. [44] reported that methylmercury ( $\mathrm{MeHg}$ ) exposure from fish intake was associated with beneficial effects in children. However, this association would be linked to the benefits of consuming fish, a food group with relatively higher levels of $\mathrm{MeHg}$. Moreover, higher prenatal $\mathrm{MeHg}$ exposure has been associated with decrements in attention, language verbal memory, motor speed and visuospatial function in other birth cohort studies [45-47]. A speciation study was not performed here, as only total $\mathrm{Hg}$ was measured in hair samples. This is a limitation, taking into account that only $\mathrm{MeHg}$ is the form of $\mathrm{Hg}$ associated with neurodevelopment impairment. Being that this is an exploratory-preliminary study, our results should be taken cautiously. On the other hand, some characteristics (i.e., social class or educational level) of the participating children and their parents may 
be different compared to those who refused to participate in the present study, therefore limiting the representativeness of the general population.

Manganese levels in human hair negatively correlated with the outcomes of the SDQ: emotional symptoms $(r=-0.372, p=0.047)$, conduct problems $(r=-0.519, p=0.004)$ and total SDQ $(r=-0.548, p=0.002)$ (Table 3). In this sample of children, higher levels of Mn tended to be related with less psychopathologic symptoms, as assessed by SDQ. Manganese levels found in this study were slightly lower than those typically reported [48]. Manganese is an essential element necessary for enzymes involved in protein metabolism, energy production and bone formation [48]. It would be plausible that, following normal dietary consumption, the systemic homeostasis of $\mathrm{Mn}$ is maintained.

Table 3. Spearman correlations between metal levels in the hair of children (boys and girls together) and neuropsychological variables $(N=53)$. SDQ, Strengths and Difficulties

Questionnaire; HRT, hit reaction time; FTT, finger-tapping test.

\begin{tabular}{ccccc}
\hline Neuropsychological Variables & Hg & Mn & Pb & U \\
\hline SDQ emotional symptoms & -0.157 & $-\mathbf{0 . 3 7 2} *$ & -0.072 & -0.093 \\
SDQ conduct problems & -0.037 & $-\mathbf{0 . 5 1 9} * *$ & -0.141 & 0.266 \\
SDQ peer relationship problems & $-\mathbf{0 . 3 7 3} * *$ & -0.158 & -0.121 & -0.070 \\
\hline Total SDQ & -0.231 & $-\mathbf{0 . 5 4 8} * *$ & -0.031 & 0.060 \\
\hline n-back: HRT 1-back number & -0.201 & -0.114 & -0.267 & -0.147 \\
n-back: HRT 2-back numbers & -0.088 & -0.040 & $-\mathbf{0 . 3 0 3} *$ & -0.282 \\
n-back: HRT 3-back-numbers & 0.002 & 0.135 & -0.212 & $-\mathbf{0 . 3 0 4} *$ \\
n-back: HRT 1-back word & 0.023 & 0.091 & -0.150 & -0.234 \\
n-back: HRT 2-back words & -0.090 & -0.072 & 0.002 & -0.173 \\
n-back: HRT 3-back words & -0.049 & -0.074 & -0.193 & $-\mathbf{0 . 4 2 7} * *$ \\
n-back: Detectability index 1-back numbers & 0.000 & 0.251 & -0.186 & $-\mathbf{0 . 4 8 7} * *$ \\
n-back: Detectability index 2-back numbers & -0.170 & -0.092 & $-\mathbf{0 . 3 3 5} *$ & $-\mathbf{0 . 3 7 4} *$ \\
n-back: Detectability index 3-back numbers & 0.072 & -0.099 & -0.082 & -0.105 \\
\hline FTT: Maximum number of repetitions with good hand & -0.061 & 0.295 & 0.156 & $\mathbf{0 . 3 3 2} *$ \\
FTT: Maximum number of repetitions with bad hand & -0.247 & 0.317 & 0.014 & $\mathbf{0 . 3 1 7} *$ \\
FTT: Summation of two times with good hand & -0.106 & 0.260 & 0.181 & $\mathbf{0 . 3 3 0} *$ \\
\hline
\end{tabular}

Asterisks indicate significant correlations at $* p<0.05$ and $* * p<0.01$; results for the rest of the metals measured are not shown, because no correlations were found.

Lead was negatively correlated with some indexes of the n-back test: HRT 2-back numbers $(r=-0.303, p=0.036)$ and detectability index remembering 2-back numbers $(r=-0.335, p=0.020)$. However, as no correlations with other tests were found, this finding should not be considered really strong. Anyhow, these results are in the same direction of previous investigations, in which $\mathrm{Pb}$ has been associated with impaired working memory, its severity being directly correlated with blood lead levels [49]. In addition, $\mathrm{Pb}$ is associated with an impaired performance in the continuous performance test (CPT) [50], and slow performance in the symbol digit test (SDS) [11]. The SDS test implies hand-eye coordination, but also attention and some kind of working memory performance. The decrease in the hit attention indicator, together with inefficacy, could suggest an impulsivity response. Some authors point out that exposure to $\mathrm{Pb}$ during childhood impairs the child's ability to allocate the cognitive resources needed to inhibit a response correctly, resulting in an increased impulsivity [51]. 
Additionally, it is not clear whether or not $\mathrm{Pb}$ might have safety levels [52], as there is no consensus around this issue yet.

Uranium levels presented negative correlations with some indicators of the n-back test: HRT 3-back numbers $(r=-0.304, p=0.048)$ and HRT 3-back words $(r=-0.427, p=0.003)$, as well as with the detectability index remembering 1-back number $(r=-0.487, p=0.001)$ and 2-back numbers $(r=-0.374, p=0.013)$. Similarly to $\mathrm{Pb}$, the current high $\mathrm{U}$ levels were related to worse working memory and impulsivity. Uranium levels in hair were also positively correlated with FTT; the maximum number of repetitions with the good hand $(r=0.332, p=0.026)$, the maximum number of repetitions with the bad hand $(r=0.317, p=0.034)$ and the addition of two times with the good hand $(r=0.330, p=0.027)$. Overall, the results of the FTT suggest a link between $U$ and speed in motor activity. Previous studies showed that rats exposed to $U$ showed less efficient working memory and increased spontaneous locomotor activity [53-55]. However, the effect of $U$ on locomotor activity is still a controversial matter [56]. The behavioral disturbances originated by $U$ might be linked to alterations of the cholinergic system, this being a target of $U$ exposure in a structure- and time-dependent manner [56,57].

Finally, phonetic fluency was positively correlated with semantic fluency $(r=0.298, p=0.030)$. The results of the phonetic fluency test indicated some correlation with gender $(r=0.276, p=0.45)$, girls being those with the highest scores. However, no correlation was found with the concentrations of metals in hair.

Despite any correlations found between the metal concentrations in hair and the outcomes of neuropsychological tests, it must be highlighted that hair may be a biomonitor of limited utility for some elements, other than As and Hg. Unfortunately, the available amount of blood from children was not sufficient to assess metal exposure. Alternatively, hair was the chosen biomonitor, because it is a non-invasive technique capable of estimating the internal exposure to heavy metals [11].

\subsection{Relationship between Testosterone Levels in Blood and Neuropsychological Tests}

In this study, we found a significant negative correlation between testosterone levels in blood and prosocial behavior in girls $(r=-0.388, p=0.041)$ (Table 4). Girls with higher testosterone levels tended to have a lower prosocial behavior. This corroborates the observations of Sisk and Zehr [15], who concluded that adolescent exposure to androgens had long-term effects on aggression in female mice. Moreover, $\mathrm{Yu}$ and Shy [58] found a positive relationship between salivary testosterone levels and the aggression factor scores of the Child Behavior Checklist (CBCL) in female students. A significant positive correlation between testosterone and detectability index remembering 3-back numbers $(r=0.520, p=0.047)$ was observed in boys. Consequently, testosterone would be related to better working memory in boys, especially with numbers. According to data from animal investigations, testosterone reduces impulsivity in male rats [59]. 
Table 4. Spearman correlations between testosterone levels in the blood of children (boys and girls separately) and neuropsychological variables $(N=44)$.

\begin{tabular}{ccc}
\hline Neuropsychological Variables & Testosterone Boys & Testosterone Girls \\
\hline Perseverations on phonetic evocation & 0.420 & $\mathbf{0 . 4 1 5} *$ \\
\hline SDQ: Prosocial behavior & -0.147 & $-\mathbf{0 . 3 8 8} *$ \\
n-back: Detectability index 3-back numbers & $\mathbf{0 . 5 2 0} *$ & -0.103 \\
FTT: Maximum number of repetitions with good hand & $-\mathbf{0 . 5 3 9} *$ & 0.334 \\
FTT: Summation of two times with bad hand & $-\mathbf{0 . 5 7 1} *$ & $\mathbf{0 . 4 2 6} *$ \\
FTT: Maximum number of repetitions with bad hand & $\mathbf{- 0 . 6 0 2} *$ & $\mathbf{0 . 4 6 2} *$ \\
\hline
\end{tabular}

Asterisks indicate a significant correlation at $* p<0.05$; results for the rest of the outcomes are not shown, because no correlations were found.

Significant positive correlations were observed between testosterone blood levels and the addition of two times with the bad hand $(r=0.426, p=0.024)$, as well as the maximum number of repetitions with the bad hand ( $r=0.462, p=0.013$ ) in girls. This indicates a relationship between testosterone and motor activity speed, with no preferred hand. Surprisingly, testosterone levels in boys were negatively correlated with the same two indexes of the finger-tapping test $(r=-0.571, p=0.021 ; r=-0.602$, $p=0.014)$ and with the maximum number of repetitions with the good hand $(r=-0.539, p=0.031)$. Previous studies failed in demonstrating that the administration of testosterone improved psychomotor performance in men $[60,61]$. It is then plausible that the correlations between testosterone and FTT could be mediated by gender. Finally, testosterone levels in girls were significantly and positively correlated with perseverations on phonetic evocation $(r=0.415, p=0.028)$. This means that high testosterone levels in girls would cause them to tend to repeat words, implying that working memory might not function as good as in girls with lower testosterone levels. No statistically significant correlations between testosterone in blood and phonetic and semantic fluencies were found (data not shown).

Because of the reduced size of the current sample, our results should be considered as very preliminary. As an exploratory study and given the small study population, we did not perform multiple test adjustments, because they are not strictly required in this kind of investigation $[62,63]$. However, since the actions of pubertal hormones during adolescence may have long-lasting consequences [15], these results should be replicated in other studies with larger sample sizes and more statistical power.

\section{Conclusions}

Although the levels of metals in hair were within standard values, $\mathrm{Pb}$ and $\mathrm{U}$ concentrations could be correlated with certain, but minor, neuropsychological alterations in the childhood population of Flix. Anyhow, the present findings should be taken cautiously. The follow-up of future birth cohorts, with bigger study populations, is needed to further evaluate the potential associations between exposure to metals and neuropsychological development in adolescence, by means of using more complex statistical analyses. 


\section{Acknowledgments}

The present research was supported by grants from Instituto de Salud Carlos III FEDER (PS09/00362) and from Institut d'Investigació Sanitària Pere Virgili (Reus, Spain), under the project 2010/IISPV/08. The authors are grateful to Rosa Maria Sabaté (primary healthcare center of Flix) for her essential support in the field work, Màrius Juanpere (Hospital de Móra d'Ebre, Spain) for his assistance in the analysis of the testosterone in blood and Ms. Beatriz Millán for her assistance in the pre-treatment of samples.

\section{Conflicts of Interest}

The authors declare no conflict of interest.

\section{References}

1. Nadal, M.; Casacuberta, N.; Garcia-Orellana, J.; Ferre-Huguet, N.; Masque, P.; Schuhmacher, M.; Domingo, J.L. Human health risk assessment of environmental and dietary exposure to natural radionuclides in the catalan stretch of the Ebro river, spain. Environ. Monit. Assess. 2011, 175, 455-468.

2. Sala, M.; Sunyer, J.; Otero, R.; Santiago-Silva, M.; Camps, C.; Grimalt, J. Organochlorine in the serum of inhabitants living near an electrochemical factory. Occup. Environ. Med. 1999, 56, 152-158.

3. Ribas-Fito, N.; Torrent, M.; Carrizo, D.; Munoz-Ortiz, L.; Julvez, J.; Grimalt, J.O.; Sunyer, J. In utero exposure to background concentrations of ddt and cognitive functioning among preschoolers. Am. J. Epidemiol. 2006, 164, 955-962.

4. Carrizo, D.; Grimalt, J.O.; Ribas-Fito, N.; Torrent, M.; Sunyer, J. In utero and post-natal accumulation of organochlorine compounds in children under different environmental conditions. J. Environ. Moni. 2007, 9, 523-529.

5. Ferre-Huguet, N.; Nadal, M.; Schuhmacher, M.; Domingo, J.L. Human health risk assessment for environmental exposure to metals in the catalan stretch of the Ebro river, Spain. Hum. Ecol. Risk Assess. 2009, 15, 604-623.

6. Esteban, M.; Castano, A. Non-invasive matrices in human biomonitoring: A review. Environ. Int. 2009, 35, 438-449.

7. Appenzeller, B.M.; Tsatsakis, A.M. Hair analysis for biomonitoring of environmental and occupational exposure to organic pollutants: State of the art, critical review and future needs. Toxicol. Lett. 2012, 210, 119-140.

8. Bellinger, D.C. Inorganic arsenic exposure and children's neurodevelopment: A review of the evidence. Toxics 2013, 1, 2-17.

9. Montuori, P.; Jover, E.; Diez, S.; Ribas-Fito, N.; Sunyer, J.; Triassi, M.; Bayona, J.M. Mercury speciation in the hair of pre-school children living near a chlor-alkali plant. Sci. Total Environ. 2006, 369, 51-58.

10. Batista, J.; Schuhmacher, M.; Domingo, J.L.; Corbella, J. Mercury in hair for a child population from Tarragona province, Spain. Sci. Total Environ. 1996, 193, 143-148. 
11. Vermeir, G.; Viaene, M.; Staessen, J.; Hond, E.D.; Roels, H.A. Neurobehavioural investigations in adolescents exposed to environmental pollutants. Environ. Toxicol. Pharmacol. 2005, 19, 707-713.

12. Torrente, M.; Colomina, M.T.; Domingo, J.L. Metal concentrations in hair and cognitive assessment in an adolescent population. Biol. Trace Elem. Res. 2005, 104, 215-221.

13. LeClair, J.A.; Quig, D.W. Mineral status, toxic metal exposure and children's behaviour. J. Orthom. Med. 2001, 16, 13-32.

14. Gooren, L. Testosterone and the brain. J. Men's Health Gend. 2007, 4, 344-351.

15. Sisk, C.L.; Zehr, J.L. Pubertal hormones organize the adolescent brain and behavior. Front. Neuroendocrinol. 2005, 26, 163-174.

16. Marshall, W.A.; Tanner, J.M. Variations in the pattern of pubertal changes in boys. Arch. Dis. Child. 1970, 45, 13-23.

17. Marshall, W.A.; Tanner, J.M. Variations in pattern of pubertal changes in girls. Arch. Dis. Child. 1969, 44, 291-303.

18. International Labour Office. ISCO-88: International Standard Classification of Occupations. Geneva: ILO. 1990. Avalaible online: http:/www2.warwick.ac.uk/fac/soc/ier/research/ classification/isco88/ (accessed on 24 December 2013).

19. Ferre-Huguet, N.; Nadal, M.; Schuhmacher, M.; Domingo, J.L. Monitoring metals in blood and hair of the population living near a hazardous waste incinerator: Temporal trend. Biol. Trace Elem. Res. 2009, 128, 191-199.

20. Nadal, M.; Bocio, A.; Schuhmacher, M.; Domingo, J.L. Trends in the levels of metals in soils and vegetation samples collected near a hazardous waste incinerator. Arch. Environ. Contam. Toxicol. 2005, 49, 290-298.

21. Kane, M.J.; Conway, A.R.; Miura, T.K.; Colflesh, G.J. Working memory, attention control, and the n-back task: A question of construct validity. J. Exp. Psychol. Learn. Mem. Cogn. 2007, 33, 615-622.

22. Deserno, L.; Sterzer, P.; Wustenberg, T.; Heinz, A.; Schlagenhauf, F., Reduced prefrontal-parietal effective connectivity and working memory deficits in schizophrenia. J. Neurosci. 2012, 32, 12-20.

23. Kortte, K.B.; Horner, M.D.; Windham, W.K. The trail making test, Part B: Cognitive flexibility or ability to maintain set? Appl. Neuropsychol. 2002, 9, 106-109.

24. Martin, A.; Wiggs, C.L.; Lalonde, F.; Mack, C. Word retrieval to letter and semantic cues: A double dissociation in normal subjects using interference tasks. Neuropsychologia 1994, 32, 1487-1494.

25. Morrison, M.W.; Gregory, R.J.; Paul, J.J. Reliability of the finger tapping test and a note on sex differences. Percept. Mot. Skills 1979, 48, 139-142.

26. Andrew, J.M. "Optimal” lateralization on the tapping test. Int. J. Neurosci. 1981, 13, 75-79.

27. Goodman, A.; Goodman, R. Strengths and difficulties questionnaire as a dimensional measure of child mental health. J. Am. Acad. Child Adolesc. Psychiatry 2009, 48, 400-403.

28. American Psychiatric Association. Diagnostic and Statistical Manual of Mental Disorders, 4th ed.; American Psychiatric Association: Washington, DC, USA, 2000. 
29. Granero, S.L.J.; Schuhmacher, M.; Corbella, J.; Domingo, J.L. Biological monitoring of environmental pollution and human exposure to metals in Tarragona, Spain. I. Levels in hair of school children. Trace Elem. Electrol. 1998, 15, 39-43.

30. Deroma, L.; Parpinel, M.; Tognin, V.; Channoufi, L.; Tratnik, J.; Horvat, M.; Valent, F.; Barbone, F. Neuropsychological assessment at school-age and prenatal low-level exposure to mercury through fish consumption in an italian birth cohort living near a contaminated site. Int. J. Hyg. Environ. Health 2013, 216, 486-493.

31. Sitdikov, F.G.; Svyatova, N.V.; Egerev, E.S. Indicators of trace-element status of children living in rural areas. Bull. Exp. Biol. Med. 2011, 152, 12-14.

32. Carneiro, M.F.; Moresco, M.B.; Chagas, G.R.; de Oliveira Souza, V.C.; Rhoden, C.R.; Barbosa, F., Jr. Assessment of trace elements in scalp hair of a young urban population in Brazil. Biol. Trace Elem. Res. 2011, 143, 815-824.

33. Lakshmi Priya, M.D.; Geetha, A. Level of trace elements (copper, zinc, magnesium and selenium) and toxic elements (lead and mercury) in the hair and nail of children with autism. Biol. Trace Elem. Res. 2011, 142, 148-158.

34. Puklova, V.; Krskova, A.; Cerna, M.; Cejchanova, M.; Rehurkova, I.; Ruprich, J.; Kratzer, K.; Kubinova, R.; Zimova, M. The mercury burden of the Czech population: An integrated approach. Int. J. Hyg. Environ. Health 2010, 213, 243-251.

35. Diez, S.; Delgado, S.; Aguilera, I.; Astray, J.; Perez-Gomez, B.; Torrent, M.; Sunyer, J.; Bayona, J.M. Prenatal and early childhood exposure to mercury and methylmercury in spain, a high-fish-consumer country. Arch. Environ. Contam. Toxicol. 2009, 56, 615-622.

36. Freire, C.; Ramos, R.; Lopez-Espinosa, M.J.; Diez, S.; Vioque, J.; Ballester, F.; Fernandez, M.F. Hair mercury levels, fish consumption, and cognitive development in preschool children from granada, Spain. Environ. Res. 2010, 110, 96-104.

37. Dongarra, G.; Lombardo, M.; Tamburo, E.; Varrica, D.; Cibella, F.; Cuttitta, G. Concentration and reference interval of trace elements in human hair from students living in Palermo, Sicily (Italy). Environ. Toxicol. Pharmacol. 2011, 32, 27-34.

38. Eastman, R.R.; Jursa, T.P.; Benedetti, C.; Lucchini, R.G.; Smith, D.R. Hair as a biomarker of environmental manganese exposure. Environ. Sci. Technol. 2013, 47, 1629-1637.

39. Temboury, M.C. Desarrollo puberal normal. Pubertad precoz. Rev. Ped. Aten. Prim. 2009, XI, s127-s142.

40. Martínez, J.P.J. Pubertad precoz y retraso puberal. Ped. Integ. 2003, VIII, 438-450.

41. Watson, W.S.; Morrison, J.; Bethel, M.I.; Baldwin, N.M.; Lyon, D.T.; Dobson, H.; Moore, M.R.; Hume, R. Food iron and lead absorption in humans. Am. J. Clin. Nutr. 1986, 44, 248-256.

42. Zimmermann, M.B.; Muthayya, S.; Moretti, D.; Kurpad, A.; Hurrell, R.F. Iron fortification reduces blood lead levels in children in Bangalore, India. Pediatrics 2006, 117, 2014-2021.

43. Choi, J.W.; Kim, S.K. Relationships of lead, copper, zinc, and cadmium levels versus hematopoiesis and iron parameters in healthy adolescents. Ann. Clin. Lab. Sci. 2005, 35, 428-434.

44. Myers, G.J.; Davidson, P.W.; Cox, C.; Shamlaye, C.; Cernichiari, E.; Clarkson, T.W. Twenty-seven years studying the human neurotoxicity of methylmercury exposure. Environ. Res. 2000, 83, $275-285$. 
45. Crump, K.S.; Kjellstrom, T.; Shipp, A.M.; Silvers, A.; Stewart, A. Influence of prenatal mercury exposure upon scholastic and psychological test performance: Benchmark analysis of a New Zealand cohort. Risk Anal. 1998, 18, 701-713.

46. Grandjean, P.; Weihe, P.; White, R.F.; Debes, F.; Araki, S.; Yokoyama, K.; Murata, K.; Sorensen, N.; Dahl, R.; Jorgensen, P.J. Cognitive deficit in 7-year-old children with prenatal exposure to methylmercury. Neurotoxicol. Teratol. 1997, 19, 417-428.

47. Debes, F.; Budtz-Jorgensen, E.; Weihe, P.; White, R.F.; Grandjean, P. Impact of prenatal methylmercury exposure on neurobehavioral function at age 14 years. Neurotoxicol. Teratol. 2006, 28, 363-375.

48. Menezes-Filho, J.A.; Bouchard, M.; Sarcinelli Pde, N.; Moreira, J.C. Manganese exposure and the neuropsychological effect on children and adolescents: A review. Rev. Panam. Salud Publica 2009, 26, 541-548.

49. Kunert, H.J.; Wiesmuller, G.A.; Schulze-Robbecke, R.; Ebel, H.; Muller-Kuppers, M.; Podoll, K. Working memory deficiencies in adults associated with low-level lead exposure: Implications of neuropsychological test results. Int. J. Hyg. Environ. Health 2004, 207, 521-530.

50. Walkowiak, J.; Altmann, L.; Kramer, U.; Sveinsson, K.; Turfeld, M.; Weishoff-Houben, M.; Winneke, G. Cognitive and sensorimotor functions in 6-year-old children in relation to lead and mercury levels: Adjustment for intelligence and contrast sensitivity in computerized testing. Neurotoxicol. Teratol. 1998, 20, 511-521.

51. Boucher, O.; Burden, M.J.; Muckle, G.; Saint-Amour, D.; Ayotte, P.; Dewailly, E.; Nelson, C.A.; Jacobson, S.W.; Jacobson, J.L. Response inhibition and error monitoring during a visual go/no-go task in inuit children exposed to lead, polychlorinated biphenyls, and methylmercury. Environ. Health Perspect. 2012, 120, 608-615.

52. Bellinger, D.C. Very low lead exposures and children's neurodevelopment. Curr. Opin. Pediatr. 2008, 20, 172-177.

53. Monleau, M.; Bussy, C.; Lestaevel, P.; Houpert, P.; Paquet, F.; Chazel, V. Bioaccumulation and behavioural effects of depleted uranium in rats exposed to repeated inhalations. Neurosci. Lett. 2005, 390, 31-36.

54. Briner, W.; Murray, J. Effects of short-term and long-term depleted uranium exposure on open-field behavior and brain lipid oxidation in rats. Neurotoxicol. Teratol. 2005, 27, 135-144.

55. Albina, M.L.; Belles, M.; Linares, V.; Sanchez, D.J.; Domingo, J.L. Restraint stress does not enhance the uranium-induced developmental and behavioral effects in the offspring of uranium-exposed male rats. Toxicology 2005, 215, 69-79.

56. Lestaevel, P.; Bensoussan, H.; Dhieux, B.; Dublineau, I.; Voisin, P.; Gourmelon, P. Cognitive and molecular responses of central nervous system after chronic exposure to uranium. Toxicol. Lett. 2010, 196S, S222.

57. Bensoussan, H.; Grancolas, L.; Dhieux-Lestaevel, B.; Delissen, O.; Vacher, C.M.; Dublineau, I.; Voisin, P.; Gourmelon, P.; Taouis, M.; Lestaevel, P. Heavy metal uranium affects the brain cholinergic system in rat following sub-chronic and chronic exposure. Toxicology 2009, 261, 59-67.

58. Yu, Y.Z.; Shi, J.X. Relationship between levels of testosterone and cortisol in saliva and aggressive behaviors of adolescents. Biomed. Environ. Sci. 2009, 22, 44-49. 
59. Wood, R.I.; Armstrong, A.; Fridkin, V.; Shah, V.; Najafi, A.; Jakowec, M. Roid rage in rats? Testosterone effects on aggressive motivation, impulsivity and tyrosine hydroxylase. Physiol. Behav. 2013, 110-111, 6-12.

60. Siegel, J.A.; Young, L.A.; Neiss, M.B.; Samuels, M.H.; Roselli, C.E.; Janowsky, J.S. Estrogen, testosterone, and sequential movement in men. Behav. Neurosci. 2008, 122, 955-962.

61. Era, P.; Alen, M.; Rahkila, P. Psychomotor and motor speed in power athletes self-administering testosterone and anabolic steroids. Res. Q. Exerc. Sport 1988, 59, 50-56.

62. Bender, R.; Lange, S. Adjusting for multiple testing - When and how? J. Clin. Epidemiol. 2001, $54,343-349$.

63. Nagakawa, S. A farewell to bonferroni: The problems of low statistical power and publication bias. Behav. Ecol. 2004, 15, 1044-1045.

(C) 2013 by the authors; licensee MDPI, Basel, Switzerland. This article is an open access article distributed under the terms and conditions of the Creative Commons Attribution license (http://creativecommons.org/licenses/by/3.0/). 